This is a pre-print of an article published in the Journal of Business Research. The final authenticated version is available online at:

Alegre, I.; Mas-Machuca, M.; Berbegal-Mirabent, J. (2016). Antecedents of employee job satisfaction: Do they matter? Journal of Business Research, 69(4): 1390-1395. https://doi.org/10.1016/j.jbusres.2015.10.113

\title{
Combined antecedents of employee job satisfaction: Do they matter?
}

\begin{abstract}
This research investigates the combined effect of (1) the employee-organization relationship, (2) the employee-supervisor relationship, and (3) the employee-coworker relationship that influences employee job satisfaction. The empirical application considers a data sample comprising 374 valid observations and uses qualitative comparative analysis in its fuzzy set variant to test the model. A second stage analysis compares the results with those obtained using alternative methodologies. The findings reveal that three different paths explain job satisfaction: (1) teamwork, identification with the strategy and the absence of employee work-life balance, (2) employee work-life balance, autonomy and identification with the strategy, and (3) supervisor support and identification with the strategy. The paper concludes with a discussion of managerial applications.
\end{abstract}

Keywords: job satisfaction, organizational goals; work-life balance; autonomy; supervisor support; teamwork 


\section{INTRODUCTION}

The academic literature has devoted considerable attention to employee job satisfaction for more than 30 years. According to Locke (1976), job satisfaction is a pleasurable or positive emotional state resulting from the appraisal of one's job or job experiences. Spector (1997) adds that employee satisfaction has become a common concern in companies. Job satisfaction is a key factor in an employee's life and is thus a stimulating topic to study.

Most academic research on job satisfaction focuses on measuring and assessing job satisfaction (Macintosh \& Krush, 2014; Spagnoli, Caetano, \& Santos, 2012; Chang \& Chen, 2014; Fila, Paik, Griffeth, \& Allen, 2014). Researchers from fields such as industrialorganizational psychology, organizational behavior and human resources management (HRM) devote significant effort to analyzing the antecedents and consequences of job satisfaction.

Most published research has a partial view on job satisfaction because usually focuses on the one-to-one relationship of an antecedent on job satisfaction, without taking a global view on how different factors simultaneously affect job satisfaction. This research posits that a combination of these factors (organization, co-workers, supervisor) affects employee job satisfaction. Accordingly, an empirical study using qualitative comparative analysis in its fuzzy sets version (fsQCA) explores the relationships between employee job satisfaction and the different relationships that employees develop in an organization. In addition, this study uses regression and structural equation models (SEM) and compares the results of the different methodologies.

This study contributes to the literature by being one of few to explore the combined effect of different relationships on job satisfaction. Second, the study extends the use of an uncommon methodology in the field of management, the fuzzy set methodology. Finally, the 
paper compares the results using fsQCA with those obtained using regression analysis and SEM, emphasizing the commonalities and differences in its application.

\section{THEORETICAL BACKGROUND}

Three main relationships affect employee satisfaction: (1) the employee-organization relationship, (2) the employee-supervisor relationship, and (3) the employee-coworker relationship (Tang, Siu, \& Cheung, 2014). The employee-organization relationship (described by Adams, King, \& King, 1996; Allen, Shore, \& Griffeth, 2003) underlines the importance of employee identification with and commitment to the organizational strategy and company goals. This relationship also includes other factors, such as a company's support of employee work-life balance. Authors such as Edgar and Geare (2005) and Fila et al. (2014), consider the employee-supervisor relationship a key influence in employee job satisfaction. Factors such as the extent to which a supervisor delegates and gives autonomy to employees greatly influence employees' assessments of their jobs. Finally, the relationship between employees and colleagues is also an important source of job satisfaction (Kirkman \& Shapiro, 2001; Sageer, Rafat, \& Agarwal, 2012). Figure 1 shows these relationships.

Figure 1 here.

Employee commitment to and identification with organizational goals requires a clear definition of those goals (Patterson, West, Shackleton, Dawson, Lawthom, Maitlis, Robinson, \& Wallace, 2005). Organizational identity refers broadly to what members perceive, feel and think about their organizations (Hatch \& Schultz, 1997). Organizational commitment exists when the individual identifies with the goals of the organization. Allen et al. (2003) suggest that employee commitment to and identification with the organization explains employee 
satisfaction. Bart, Bontis, and Taggar (2001) link employee satisfaction with the organizational mission and strategy.

Most employees divide their daily life between work and family. Therefore, organizational responses to work-family (WF) conflict influence employees' attitudes toward their jobs (Ornstein \& Isabella, 1993). Research by Kossek and Ozeki (1998) explores the relationship between WF conflict, organizational policies, and job and life satisfaction. The results show a consistent negative relationship between WF conflict and job and life satisfaction. Dixon and Sagas (2007) empirically demonstrate the theorized relationship between WF conflict and job-life satisfaction. Qu and Zhao (2012) investigate the impact of life satisfaction on job satisfaction in different situations of WF conflict.

Rowold, Borgmann, and Bormann (2014) propose that leadership style positively affects employees' organizational commitment and job satisfaction. In particular, the extent to which an employee's supervisor provides encouragement and support to the employee with regard to the employee's work is a strong determinant of the employee's attitude toward his or her job (Griffin, Patterson, \& West, 2001). Studies investigating this relationship are common in a wide array of jobs (Yukl, 1989). Kirkman and Rosen (1999) underline the importance of promoting a supportive work environment and adequate supervisor support, which affect employees' work-related attitudes and perceptions. Tang et al. (2014) suggest that WF enrichment fully mediates the relationship between supervisors and organizational support with job satisfaction.

Autonomy is the extent to which individual employees can structure and control how and when they perform their specific job. Highly autonomous jobs enhance performance and job satisfaction (Spector, 1986). Autonomy and flexibility are common antecedents of job satisfaction (Griffin et al., 2001; Chang \& Cheng, 2014). 
Finally, teamwork reflects the relationship between employees and colleagues by involving interdependent groups that work cooperatively to obtain an outcome (Parker \& Wall, 1998). The increased interest in teamwork emerges from the idea that work teams are able to generate greater returns than are individuals alone (Ilgen, Hollenbeck, Johnson, \& Jundt, 2005). The collaboration and sharing of information and knowledge within a team and the prioritization of the group over individual outcomes are important team features to enhance teamwork benefits. According to Griffin et al. (2001), the associated job enrichment partly explains the link between teamwork and job satisfaction. Work policies related to job enrichment and initiatives produce increased levels of autonomy.

The previous studies mainly employ SEM, hierarchical regression analysis or metaanalytic combinations. Job satisfaction involves a person's overall evaluation of the relationships mentioned above. To better understand the combined antecedents of job satisfaction, this study proposes the use of fsQCA.

\section{DATA AND METHOD}

\section{Sample and procedure}

The sample includes employees of a Spanish pharmaceutical company. The fieldwork contains information of 463 surveys (March 2013) using both online and paper-and-pencil formats. After discarding incomplete questionnaires with more than two unanswered items, 374 valid surveys provide the final data for analysis (a response rate of $80.78 \%$ ). The mean of nearby points helps replacing missing data points. Support from management and participation strategies such as a raffle facilitate the high response rate. 


\section{Scales}

The survey includes six scales (identification with and commitment to organizational goals, work-life balance, autonomy, supervisor support, teamwork and job satisfaction) in the form of statements to which respondents indicate their level of agreement/disagreement on a four-point Likert scale. All item loadings are higher than 0.6. The original language of the items in the scales is English. This study applies forward/backward translation (FBT) to adapt the questionnaire (Chen \& Bates, 2005).

An extensive review of the relevant literature supports the scales (see Table 1).

Table 1 here.

Lastly, one single-item overall measure captures job satisfaction. According to Dolbier, Webster, McCalister, Mallon, and Steinhardt (2005), and Wanous, Reichers, and Hudy (1997), from a psychometric perspective, single-item measures to operationalize this construct compare favorably with multiple-item measures.

\section{Methodology}

This study uses qualitative comparative analysis (QCA) in its fuzzy-set variant (fsQCA). QCA addresses complex causality perspectives by assuming asymmetric relationships among observations. This approach facilitates the determination of which combination of antecedent conditions is most likely to cause an outcome. The result is a number of combinations that enable the production of the outcome under analysis (Longest \& Vaisey, 2008).

QCA entails the analysis of the necessary and sufficient conditions to produce the desired outcome (Meyer, Tsui, \& Hinings, 1993; Wu, Yeh, Huan, \& Woodside, 2014) and involves various stages. First, a calibration process transforms variables into sets according to their 
degree of membership in a given condition (Ragin, 2008). A score of "1" indicates full membership, and "0" full non-membership. Breakpoints allow for the calibration of all original values into membership values. Typically, 0.95 indicates full membership, and 0.05 denotes full non-membership. The crossover point (0.5) designates cases with the maximum ambiguity of their membership in the set.

The second stage includes the analysis of the truth table, which consists of all logically possible combinations of condition sets (Fiss, 2011). Next, using Boolean algebra, QCA computes the commonalities among the configurations that lead to the outcome. Lastly, the Quine-McCluskey algorithm performs a logical reduction of statements (Fiss, 2007; Quine, 1955). At this stage, two parameters are in order: (a) coverage and (b) consistency. The former indicates the empirical relevance of a solution (the higher the better), and the latter quantifies the extent to which cases that share similar conditions display the same outcome.

The STATA software package (version 13) supports the statistical treatment of the data.

\section{RESULTS}

Table 2 shows the calibration process and indicates the transformation into fuzzy terms of both the outcome and the antecedent conditions.

Table 2 here.

Tables 2 and 3 show the relationship between the outcome (job satisfaction) and the various antecedent conditions considered. Table 3 shows that all causal conditions considered relate with the outcome variable, with coincidence scores above 0.85 in all cases. As indicated in Table 4, no single set (alone) is most sufficient for predicting the outcome. 
Table 3 here.

Variable sets are related, so the analysis can proceed to examine the consistency of different configurations when causal conditions are combined.

The first step involves identifying configurations that have y-consistencies (positive outcome) that are significantly greater than their n-consistencies (negation of the outcome). According to the results displayed in Table 4, 23 configurations fulfill the requirements. Following the nomenclature, factors in uppercase letters indicate the presence of that condition, whereas lowercase letters denote its absence.

The second stage involves determining which configurations have y-consistency levels significantly higher than a threshold value. According to Ragin (2008), a minimum consistency of 0.8 is sufficient to indicate goodness of fit. This study employs a cutoff point of 0.900 for greater stringency and to obtain a more restricted number of conditions that fulfill the requirement. The figures in Table 4 indicate that for the given input, twelve configurations are consistent at the 0.05 level of significance.

Table 4 here.

The next step consists of selecting only those configurations that passed both tests. Twelve common sets are found; however, they may overlap. The Quine-McCluskey algorithm is used to perform the reduction. The final reduction set includes three configurations, indicating that the configurations displayed in Table 4 are collapsed into three. Table 5 shows the results. Each row represents a configuration of causal conditions. For each of these configurations, raw and unique coverage and consistency are calculated. The numbers at the bottom of the 
table represent the coverage and consistency of the solution as a whole. According to the results of the analysis, the solution yields coverage close to $60 \%$ and consistency of $91.6 \%$.

Table 5 here.

The first configuration of the solution, teamwork*strategy* $\sim$ worklife, establishes the combination of factors that lead to job satisfaction: teamwork and cooperation between employees, identification with the strategy of the company, and the absence of employee work-life balance. This configuration indicates that when employees identify with the organizational strategy and a positive relationship exists with colleagues and team members, even if the job is demanding and reconciling work and family is difficult it is possible to achieve positive levels of job satisfaction. In this case, employees who are aligned with the organizational strategy and supported by team members and colleagues enjoy being at work, even at a certain personal cost.

The second combination of antecedent conditions is autonomy*strategy*worklife. In contrast to the previous recipe, here, employee work-life balance is relevant for job satisfaction, as are autonomy and identification with the organizational strategy. This case opposes the previous configuration; here, employees value job autonomy, which allows employees to make their own decisions about their work and schedule, thereby facilitating work-life balance. Employees appreciate their job because of the autonomy inherent in the job, which contrasts with the previous configuration, in which employees value team membership and collaboration.

The third configuration that emerges from the analysis (supervisor*strategy) indicates that a combination of supervisor support and identification with the strategy also lead to job satisfaction. This formula covers another source of support for an employee in addition to 
colleagues: supervisor support. In this sense, supervisor support enhances job satisfaction. Notably, in all three configurations mentioned above, employee identification with the organizational strategy is a significant factor in achieving positive levels of job satisfaction.

To further corroborate the results, additional tests use regression analysis and SEM. Although all these methodologies differ in scope and purpose, comparing the results obtained using dissimilar approaches would lead to interesting results, not only in terms of the predicting models but in terms of methodological issues.

First, this study conducts a regression analysis to examine the explanatory power of the five factors included in the model on the outcome (job satisfaction). The findings reveal that both supervisor support ( $\mathrm{p}$-value $=0.003$ ) and employees' identification with the strategy of the firm (p-value $=0.000$ ) positively relates with job satisfaction. Normal probability plots of the residuals corroborate that they are normally distributed. Additionally, no collinearity problems appear, as the maximum VIF is 2.46 (Rogerson, 2001).

Concerning the use of SEM, the study uses the maximum likelihood method from the asymptotic variance-covariance matrix to estimate the model. The empirical work employs EQS software version 6.1. The fit indices in the measurement model estimation show good general fitness, $\chi^{2}=87.580$ with 63 degrees of freedom and a $p$-value of $0.0220 ; \chi^{2} / \mathrm{df}$ is 1.39 , under the acceptable limit of 5; RMSEA is 0.032; and the CFI is 0.988. Although the model fit is appropriate, the results provide support only for the argument that employees' identification with the strategy of the firm is the only factor that exerts a significant influence on job satisfaction. Supervisor support is close to being significant but does not enter in the model.

These two complementary methodologies suggest that in both cases, the results seem to support the above argument that employee identification with organizational strategy is a key factor that affects job satisfaction. 


\section{DISCUSSION}

The results contribute to the research on job satisfaction by outlining several combinations of antecedents that affect employee job satisfaction. A high level of teamwork and a high level of identification and commitment with the company's strategy despite a low level of work-life balance create high levels of job satisfaction. Thus, when an employee has a good relationship with his/her colleagues and identifies with the company's objectives and goals despite a possible work-family conflict, it is possible to achieve employee satisfaction. In part, well-being with one's coworkers and identification with the direction and aim of the company compensate for the interference of work-family conflict. For those employees, working in the company requires an effort with respect to family obligations and life satisfaction; nevertheless, a friendly environment and the identification with the company's goals improve job satisfaction.

In addition, the empirical results indicate that higher levels of autonomy in the decisionmaking process, increased levels of identification and commitment with organizational goals and higher levels of work-family balance for employees produce high levels of job satisfaction. When employees share the organization's strategy and mission, have autonomy to structure and manage their work and can balance their work with family or leisure, their job satisfaction is high.

Also notable is the combined effect of the identification with organizational goals and supervisor support. When a company's strategy aligns with managerial help, job satisfaction increases. Employees feel comfortable in the company if they share the organization's mission (Bart et al., 2001). Furthermore, employees need to be comfortable with their supervisor. These two factors can explain employee job satisfaction.

As predicted, the findings are clearly in favor of the view that job satisfaction is a complex variable and that many types of relationships shape it. These different standpoints contribute 
to a better understanding of the job satisfaction construct. An avenue for achieving satisfaction and well-being in employees is to develop practices or initiatives aimed at increasing perceptions of organizational commitment, work-family balance, autonomy, supervisor support and collaboration in teamwork.

\section{CONCLUSION}

This paper contributes to a large body of work on the antecedents of job satisfaction. The results agree with previous research on employee satisfaction, underlying important relationships such as employee-organization, employee-coworkers and employee-supervisor relationships. However, whereas previous studies scrutinize the one-to-one relationship of these factors with job satisfaction, this study contributes to different research streams on job satisfaction by studying the effect of all of these relationships simultaneously. Research on human resource management, psychology and general management can also profit from the approach and methodology that this study adopts. Despite information science and operations research apply QCA, this methodology is largely unknown in the managerial literature. The application of fuzzy set methodology in an area dominated by regressions and SEM can offer multiple research opportunities to business and management scholars. This paper contributes to widening the scope and application of new quantitative techniques and compares several methodologies and results.

The results of this research also have practical implications for management because they may help managers to understand the causes of higher levels of job satisfaction in a more holistic manner. How can a firm satisfy its employees? This question is relevant for practice.

This research has several limitations, the most critical of which relates to the data source. Data in this study come from a single Spanish company, thus calling into question the generalizability of the results. Nevertheless, the subject of interest is at the individual level, 
and the company has several sites and differentiated departments to ensure that the variables studied, such as employees' relationships with their team members and supervisors, have the necessary variability.

Future research could replicate our study in more companies and in more countries or regions. Additionally, future studies could include other organizational variables (e.g., leadership, communication, internal processes) to examine the possible mediating or moderating roles in the relationship.

\section{REFERENCES}

Adams, G. A., King, L. A., \& King, D. W. (1996). Relationships of job and family involvement, family social support, and work-family conflict with job and life satisfaction. Journal of Applied Psychology, 81(4), 411.

Allen, D. G., Shore, L. M., \& Griffeth, R. W. (2003). The role of perceived organizational support and supportive human resource practices in the turnover process. Journal of Management, 29, 99-118.

Bart, C. K., Bontis, N., \& Taggar, S. (2001). A model of the impact of mission statements on firm performance. Management Decision, 39, 19-35.

Chang, M. L., \& Cheng, C. F. (2014). How balance theory explains high-tech professionals' solutions of enhancing job satisfaction. Journal of Business Research, 67, 2008-2018.

Chen, H., and Bates, R.A. (2005). Instrument Translation and Development Strategies for CrossCultural Studies, Proceedings of the Academy of Human Resource Development, pp. 693-700. 
Dixon, M. A., \& Sagas, M. (2007). The relationship between organizational support, workfamily conflict, and the job-life satisfaction of university coaches. Research Quarterly for Exercise and Sport, 78, 236-247.

Dolbier, C. L., Webster, J. A., McCalister, K. T., Mallon, M. W., \& Steinhardt, M. A. (2005). Reliability and validity of a single-item measure of job satisfaction. American Journal of Health Promotion, 19, 194-198.

Edgar, F., \& Geare, A. (2005). HRM practice and employee attitudes: different measures different results. Personnel Review, 34, 534-549.

Fila, M. J., Paik, L. S., Griffeth, R. W., \& Allen, D. (2014). Disaggregating Job satisfaction: effects of perceived demands, control, and support. Journal of Business and Psychology, 29, 639-649.

Fiss, P. C. (2007). A set-theoretic approach to organizational configurations. Academy of Management Review, 32, 1180-1198.

Fiss, P. C. (2011). Building better causal theories: a fuzzy set approach to typologies in organization research. Academy of Management Journal, 54, 393-420.

Griffin, M. A., Patterson, M. G., \& West, M. A. (2001). Job satisfaction and teamwork: the role of supervisor support. Journal of Organizational Behavior, 22, 537-550.

Hatch, M.J., \& Schultz, M. (1997).Relations between organizational culture, identity and image. European Journal of Marketing, 31(5/6), 356-365.

Hayman, J. (2005). Psychometric assessment of an instrument designed to measure work life balance. Research and Practice in Human Resource Management, 13, 85-91.

Ilgen, D. R., Hollenbeck, J. R., Johnson, M., \& Jundt, D. (2005). Teams in organizations: from input-process-output models to IMOI models. Annual Review of Psychology, 56, 517-543. 
Kirkman, B. L., \& Rosen, B. (1999). Beyond self-management: antecedents and consequences of team empowerment. Academy of Management Journal, 42, 58-74.

Kirkman, B. L., \& Shapiro, D. L. (2001). The impact of cultural values on job satisfaction and organizational commitment in self-managing work teams: the mediating role of employee resistance. Academy of Management Journal, 44, 557-569.

Kossek, E., \& Ozeki, C. (1998). Work-family conflict, policies, and the job-life satisfaction relationship: A review and directions for organizational behavior-human resources research. Journal of Applied Psychology, 83, 139-149.

Locke, E. A. (1976). The nature and causes of job satisfaction. In M. D. Dunnette (Ed.), Handbook of industrial \& organizational psychology. Chicago: Rand-McNally.

Longest, K. C., \& Vaisey, S. (2008). Fuzzy: A program for performing qualitative comparative analyses (QCA) in Stata. STATA Journal, 8, 79-104.

Macintosh, G., \& Krush, M. (2014). Examining the link between salesperson networking behaviors, job satisfaction, and organizational commitment: Does gender matter?. Journal of Business Research, 67, 2628-2635.

Meyer, A. D., Tsui, A. S., \& Hinings, C. R. (1993). Configurational approaches to organizational analysis. Academy of Management Journal, 36, 1175-1195.

Ornstein, S., \& Isabella, L. A. (1993). Making sense of careers: A review 1989-1992. Journal of Management, 19, 243-267.

Parker, S. K., \& Wall, T. D. (1998). Job and work design: Organizing work to promote wellbeing and effectiveness (Vol. 4). London: SAGE.

Patterson, M. G., West, M. A., Shackleton, V. J., Dawson, J. F., Lawthom, R., Maitlis, S., \& Robinson, D. L., Wallace, A. M. (2005). Validating the organizational climate measure: Links to managerial practices, productivity and innovation. Journal of Organizational Behavior, 26, 379-408. 
Rowold, J., Borgmann, L., \& Bormann, K. (2014). Which Leadership Constructs Are Important for Predicting Job Satisfaction, Affective Commitment, and Perceived Job Performance in Profit versus Nonprofit Organizations?. Nonprofit Management and Leadership, 25(2), 147-164.

Qu, H., \& Zhao, X. R. (2012).Employees' work-family conflict moderating life and job satisfaction. Journal of Business Research, 65, 22-28.

Quine, W. V. (1955). A way to simplify truth functions. The American Mathematical Monthly, 62, 627-631.

Ragin, C. C. (2008). Redesigning social inquiry: Fuzzy sets and beyond. Chicago: University of Chicago Press.

Rogerson, P. (2001). Statistical methods for geography. London: SAGE Publications.

Sageer, A., Rafat, S., \& Agarwal, P. (2012). Identification of variables affecting employee satisfaction and their impact on the organization. IOSR. Journal of Business and Management, 5, 32-39.

Spagnoli, P., Caetano, A., \& Santos, S. C. (2012). Satisfaction with job aspects: Do patterns change over time?. Journal of Business Research, 65, 609-616.

Spector, P. E. (1986). Perceived control by employees: A meta-analysis of studies concerning autonomy and participation at work. Human Relations, 39, 1005-1016.

Spector, P. E. (1997). Job satisfaction: Application, assessment, causes, and consequences (Vol. 3). London: SAGE.

Tang, S. W., Siu, O. L., \& Cheung, F. (2014). A study of work-family enrichment among Chinese employees: The mediating role between work support and job satisfaction. Applied Psychology, 63, 130-150.

Wanous, J. P., Reichers, A. E., \& Hudy, M. J. (1997). Overall job satisfaction: How good are single-item measures?Journal of Applied Psychology, 82, 247-252. 
Wu, P., Yeh, S., Huan, T. C., \& Woodside, A. G. (2014). Applying complexity theory to deepen service dominant logic: Configural analysis of customer experience-andoutcome assessments of professional services for personal transformations. Journal of Business Research, 67, 1647-1670.

Yukl, G. (1989). Managerial leadership: A review of theory and research. Journal of Management, 15, 251-289. 


\section{List of figures}

Figure 1. Relationships between employees at different levels

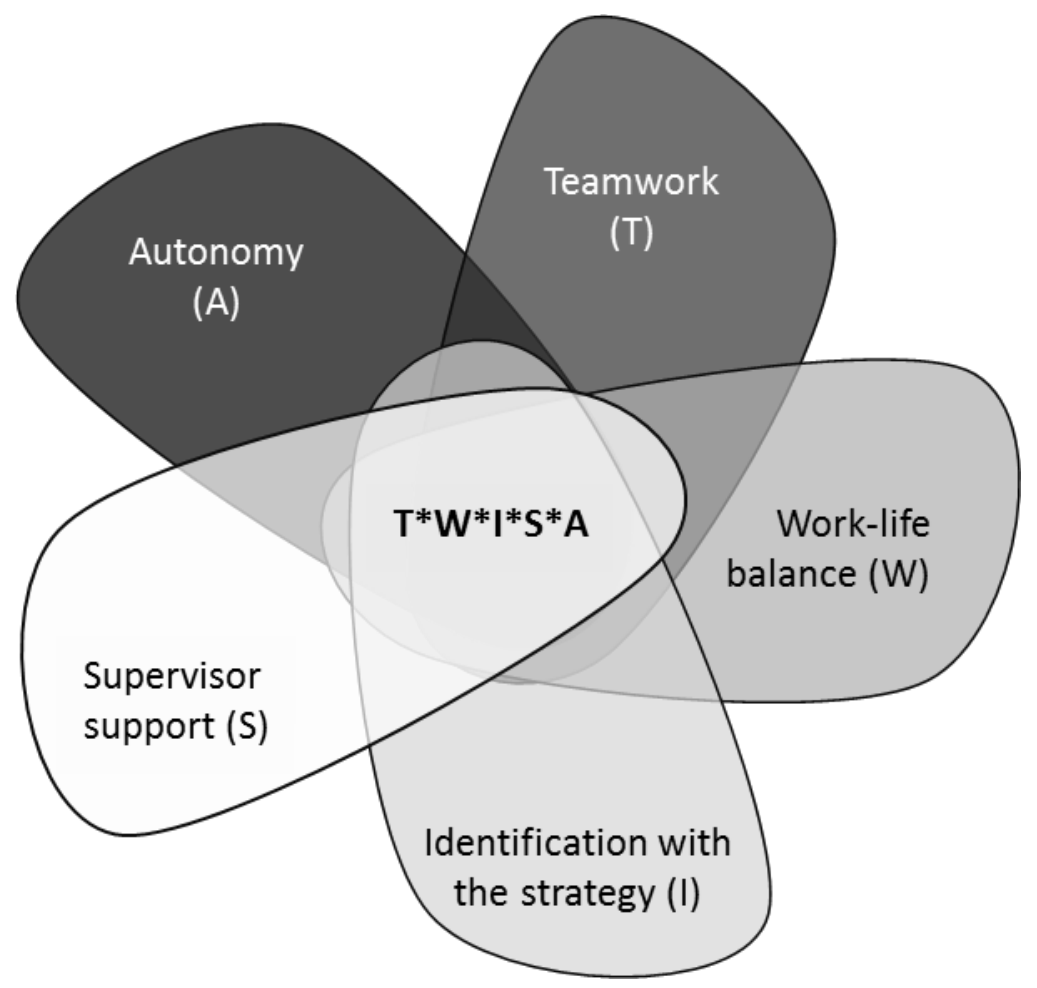




\section{List of tables}

Table 1. Scales measurements

\begin{tabular}{|c|c|c|c|}
\hline Construct & Original construct & Adapted from & $\begin{array}{c}\text { Cronbach's } \\
\text { alpha }\end{array}$ \\
\hline Autonomy & Autonomy & \multirow{4}{*}{$\begin{array}{l}\text { Organizational Climate } \\
\text { Measure (OMC) } \\
\text { Patterson et al. (2005) }\end{array}$} & 0.68 \\
\hline Teamwork & Integration & & 0.74 \\
\hline Supervisor support & Supervisor support & & 0.816 \\
\hline $\begin{array}{l}\text { Identification with the } \\
\text { strategy }\end{array}$ & $\begin{array}{l}\text { Clarity of } \\
\text { organizational goals }\end{array}$ & & 0.80 \\
\hline $\begin{array}{l}\text { Employee work-life } \\
\text { balance }\end{array}$ & Work-life family & Hayman (2005) & 0.74 \\
\hline
\end{tabular}

Table 2. Distribution of each variable and its corresponding set

\begin{tabular}{|l|c|c|c|c|}
\hline \multicolumn{1}{|c|}{ Variable } & Coding & $\begin{array}{c}\text { Full non- } \\
\text { membership } \\
\mathbf{( 0 . 0 5 )}\end{array}$ & $\begin{array}{c}\text { Crossover } \\
\text { point } \\
(\mathbf{0 . 5})\end{array}$ & $\begin{array}{c}\text { Full } \\
\text { membership } \\
(\mathbf{0 . 9 5 )}\end{array}$ \\
\hline Job satisfaction & jobsat & 0.150 & 1.500 & 2.850 \\
\hline Autonomy & autonomy & 0.248 & 2.484 & 4.719 \\
\hline Teamwork & teamwork & 0.308 & 3.075 & 5.843 \\
\hline Supervisor support & supervisor & 0.314 & 3.137 & 5.960 \\
\hline Identification with the strategy & strategy & 0.358 & 3.578 & 6.797 \\
\hline Employee work-life balance & worklife & 0.232 & 2.315 & 4.398 \\
\hline
\end{tabular}


Table 3. Coincidence matrix and sufficiency and necessity matrix

\begin{tabular}{|c|c|c|c|c|c|c|}
\hline \multicolumn{7}{|c|}{ Coincidence matrix } \\
\hline & jobsat & autonomy & teamwork & supervisor & strategy & worklife \\
\hline jobsat & 1.000 & & & & & \\
\hline autonomy & 0.869 & 1.000 & & & & \\
\hline teamwork & 0.888 & 0.809 & 1.000 & & & \\
\hline supervisor & 0.897 & 0.832 & 0.831 & 1.000 & & \\
\hline strategy & 0.874 & 0.790 & 0.805 & 0.806 & 1.000 & \\
\hline worklife & 0.834 & 0.768 & 0.726 & 0.750 & 0.757 & 1.000 \\
\hline \multicolumn{7}{|c|}{ Sufficiency and necessity matrix } \\
\hline & jobsat & autonomy & teamwork & supervisor & strategy & worklife \\
\hline jobsat & 1.000 & 0.626 & 0.608 & 0.645 & 0.674 & 0.595 \\
\hline autonomy & 0.869 & 1.000 & 0.770 & 0.831 & 0.790 & 0.760 \\
\hline teamwork & 0.888 & 0.809 & 1.000 & 0.831 & 0.805 & 0.726 \\
\hline supervisor & 0.897 & 0.832 & 0.831 & 1.000 & 0.806 & 0.743 \\
\hline strategy & 0.874 & 0.790 & 0.805 & 0.806 & 1.000 & 0.700 \\
\hline worklife & 0.834 & 0.768 & 0.726 & 0.750 & \begin{tabular}{|l|}
0.757 \\
\end{tabular} & 1.000 \\
\hline
\end{tabular}

Table 4. Sufficiency and necessity matrix

\begin{tabular}{|c|c|c|c|c|}
\hline \multicolumn{5}{|l|}{ Y-CONSISTENCY vS. N-CONSISTENCY } \\
\hline Set & YCons & NCons & $\mathrm{F}$ & $\mathrm{P}$ \\
\hline autonomy* ${ }^{*}$ teamwork*supervisor* $\sim$ strategy* worklife & 0.915 & 0.439 & 96.45 & 0 \\
\hline autonomy* ${ }^{*}$ teamwork*supervisor*strategy* $\sim$ worklife & 0.944 & 0.383 & 185.24 & 0 \\
\hline autonomy* teamwork*supervisor*strategy*worklife & 0.950 & 0.363 & 218.2 & 0 \\
\hline$\sim$ autonomy*teamwork ${ }^{*} \sim$ supervisor* $\sim$ strategy* ${ }^{*}$ worklife & 0.908 & 0.455 & 85.85 & 0 \\
\hline autonomy*teamwork ${ }^{*} \sim$ supervisor*strategy* $\sim$ worklife & 0.931 & 0.393 & 146.72 & 0 \\
\hline$\sim$ autonomy*teamwork ${ }^{*} \sim$ supervisor* strategy $^{*} \sim$ worklife & 0.926 & 0.395 & 129.64 & 0 \\
\hline$\sim$ autonomy*teamwork* ${\text { supervisor* }{ }^{*} \sim \text { strategy } * \sim \text { worklife }}^{*}$ & 0.922 & 0.406 & 117.97 & 0 \\
\hline 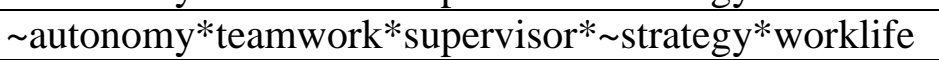 & 0.927 & 0.394 & 130.13 & 0 \\
\hline autonomy*teamwork*supervisor*strategy* $\sim$ worklife & 0.952 & 0.342 & 243.09 & 0 \\
\hline autonomy*teamwork*supervisor*strategy*worklife & 0.952 & 0.328 & 268.65 & 0 \\
\hline autonomy* ${ }^{*}$ teamwork $*$ supervisor* strategy $^{*} \sim$ worklife & 0.926 & 0.421 & 124.62 & 0 \\
\hline autonomy* ${ }^{*}$ teamwork* $\sim$ supervisor*strategy*worklife & 0.943 & 0.367 & 192.59 & 0 \\
\hline 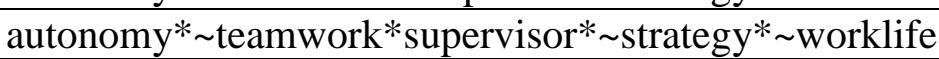 & 0.913 & 0.427 & 99.04 & 0 \\
\hline autonomy* teamwork* $^{*}$ supervisor* strategy* worklife $^{*}$ & 0.928 & 0.372 & 147.82 & 0 \\
\hline autonomy* teamwork*supervisor*strategy* $\sim$ worklife & 0.936 & 0.368 & 169.55 & 0 \\
\hline autonomy* ${ }^{*}$ teamwork* supervisor*strategy*worklife & 0.953 & 0.301 & 304.67 & 0 \\
\hline autonomy*teamwork* ${ }^{*} \sim$ supervisor* ${ }^{*} \sim$ strategy* worklife & 0.910 & 0.403 & 103.64 & 0 \\
\hline autonomy*teamwork* ${ }^{*}$ supervisor*strategy* $\sim$ worklife & 0.933 & 0.377 & 151.64 & 0 \\
\hline autonomy*teamwork* ${ }^{*}$ supervisor*strategy*worklife & 0.943 & 0.339 & 220.31 & 0 \\
\hline autonomy*teamwork*supervisor* $\sim$ strategy $* \sim$ worklife & 0.913 & 0.373 & 117.31 & 0 \\
\hline autonomy*teamwork*supervisor* ${ }^{*}$ strategy*worklife & 0.922 & 0.327 & 165.36 & 0 \\
\hline autonomy*teamwork* supervisor* strategy* $\sim$ worklife $^{*}$ & 0.953 & 0.268 & 343.43 & 0 \\
\hline autonomy*teamwork*supervisor*strategy*worklife & 0.946 & 0.213 & 464.72 & 0 \\
\hline
\end{tabular}




\begin{tabular}{|c|c|c|c|c|}
\hline \multicolumn{5}{|l|}{ Y-Consistency vs. Set Value } \\
\hline Set & YConsist & $\begin{array}{c}\text { Set } \\
\text { Value }\end{array}$ & $\mathrm{F}$ & $\mathrm{P}$ \\
\hline$\sim$ autonomy* ${ }^{*}$ teamwork*supervisor*strategy* $\sim$ worklife & 0.944 & 0.9 & 15.54 & 0 \\
\hline autonomy* teamwork*supervisor*strategy*worklife & 0.950 & 0.9 & 20.77 & 0 \\
\hline$\sim$ autonomy*teamwork ${ }^{*} \sim$ supervisor*strategy* $\sim$ worklife & 0.931 & 0.9 & 5.42 & 0.020 \\
\hline autonomy*teamwork*supervisor*strategy* $\sim$ worklife & 0.952 & 0.9 & 27.06 & 0 \\
\hline autonomy*teamwork*supervisor*strategy*worklife & 0.952 & 0.9 & 25.69 & 0 \\
\hline autonomy* teamwork* $\sim$ supervisor*strategy*worklife & 0.943 & 0.9 & 11.78 & 0.001 \\
\hline autonomy* ${ }^{*}$ teamwork*supervisor*strategy* $\sim$ worklife & 0.936 & 0.9 & 6.47 & 0.011 \\
\hline autonomy* teamwork*supervisor*strategy*worklife & 0.953 & 0.9 & 20.64 & 0 \\
\hline autonomy*teamwork ${ }^{*} \sim$ supervisor* strategy* $\sim$ worklife & 0.933 & 0.9 & 4.66 & 0.032 \\
\hline autonomy*teamwork* ${ }^{*}$ supervisor*strategy*worklife & 0.943 & 0.9 & 11.14 & 0.001 \\
\hline autonomy*teamwork*supervisor*strategy* $\sim$ worklife & 0.953 & 0.9 & 21.07 & 0 \\
\hline autonomy*teamwork*supervisor*strategy*worklife & 0.946 & 0.9 & 15.58 & 0 \\
\hline \multicolumn{5}{|l|}{ Common sets } \\
\hline \multicolumn{5}{|l|}{ 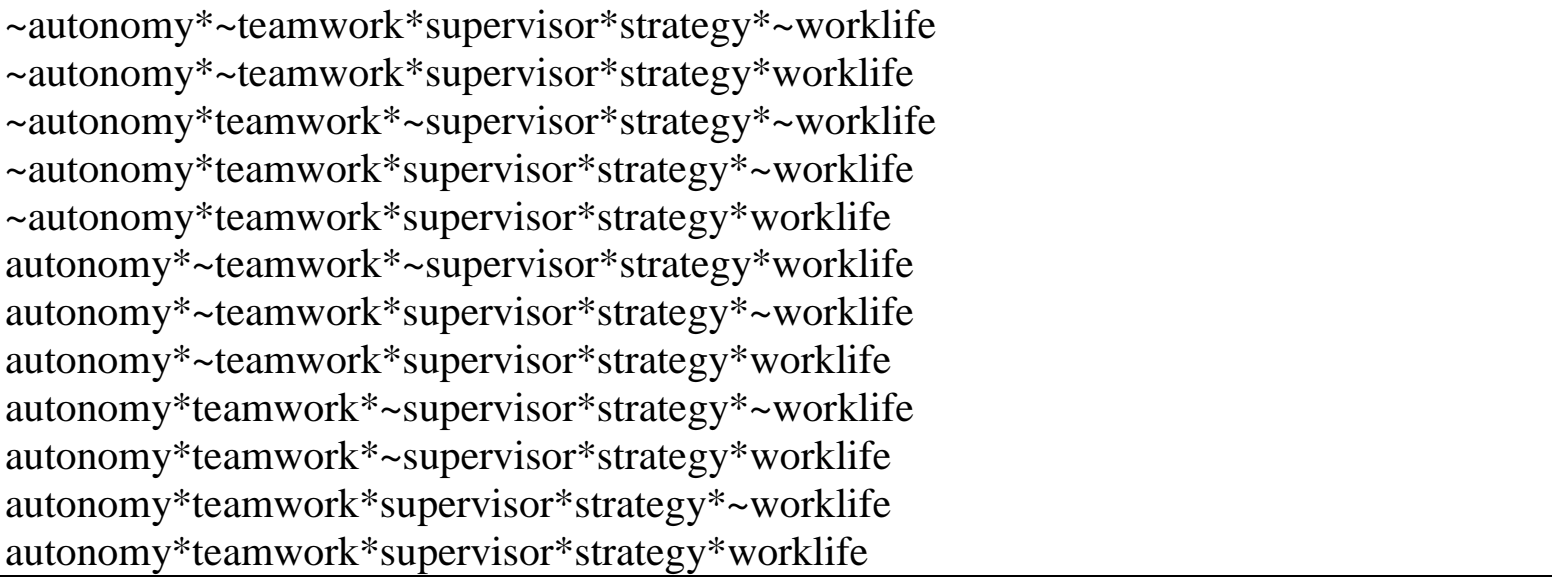 } \\
\hline
\end{tabular}

Table 5. Sufficiency and necessity matrix

\begin{tabular}{|l|c|c|c|}
\hline \multicolumn{1}{|c|}{ Set configurations } & $\begin{array}{c}\text { Raw } \\
\text { coverage }\end{array}$ & $\begin{array}{c}\text { Unique } \\
\text { coverage }\end{array}$ & $\begin{array}{c}\text { Solution } \\
\text { consistency }\end{array}$ \\
\hline teamwork* $\sim$ strategy* $\sim$ worklife & 0.301 & 0.025 & 0.933 \\
\hline autonomy*strategy*worklife & 0.425 & 0.022 & 0.930 \\
\hline supervisor*strategy & 0.538 & 0.070 & 0.929 \\
\hline Total coverage $=0.591$ & \multicolumn{3}{|l}{} \\
\hline Solution consistency $=0.916$
\end{tabular}

